\title{
THE NATIONAL SCIENCE FOUNDATION PROGRAM IN MATHEMATICS
}

\author{
ALAN T. WATERMAN
}

I am very happy to have this opportunity of meeting with the members of the American Mathematical Society and the Mathematical Association of America here in our neighbor-city, Baltimore.

The Foundation considers itself fortunate indeed in the advice and assistance we have had and are enjoying from members of this group. As you know, Professor Marston Morse is one of the twenty-four members of the National Science Board. Professor William Duren of Tulane University was most helpful in the initial planning of our mathematics program. We are pleased to have as program director for mathematics, your colleague, Dr. Leon Cohen, who came to us this year from Queens College, where he had been Associate Professor of Mathematics since 1947. Dr. Cohen has been with us only a few months and in that time he has made real progress toward the development of a National Science Foundation program in mathematics. Perhaps it may interest you to know something of that program. NSF activities in the field fall in several categories: conferences, institutes, grants, research seminars, the regional development of mathematics, support of publications, fellowship support.

Last May a Conference on Fiber Bundles and Differential Geometry was held at Cornell University, under the chairmanship of Dr. Norman Steenrod of Princeton. As you know, the Foundation sponsored, jointly with the American Mathematical Society, the Summer Institute on Lie Groups and Lie Algebras at Colby College, under the chairmansip of Dr. Nathan Jacobson of Yale University. I believe I am correct in saying that there was considerable enthusiasm for this institute as well as the hope that it may be the first in a series. It is my understanding that plans are now under way for a second summer institute on the functions of several complex variables, under the leadership of Dr. Salomon Bochner of Princeton.

A Foundation grant to the National Research Council for a study of training in, and the subject matter of, applied mathematics re-

An address delivered at the dinner at the Joint Meeting of the American Mathematical Society and the Mathematical Association of America in Baltimore, December 30, 1953; received by the editors February 5, 1954. 
sulted in two conferences: one which was held in conjunction with the October meeting of the American Mathematical Society in New York on training in applied mathematics, and a conference that was held in conjunction with the November meeting of the AMS in Evanston on the subject of applied mathematics. The survey was brought about through the efforts of Dr. F. J. Weyl of the Office of Naval Research.

I am sure that most of you are by now acquainted with the summer institute for teachers of collegiate mathematics that was sponsored by the National Science Foundation last summer. Under the very able direction of Dr. Burton Jones, the institute was conducted for six weeks at the University of Colorado in Boulder. The purpose of this institute was to acquaint teachers of mathematics, particularly from the smaller colleges, with some of the latest developments in the field. The institute attracted about 75 participants, representing all sections of the United States. Members of the institute lived in the residence halls and their meals were served in the college dining room. These arrangements made it possible for the participants in the conference to get to know each other very well and to hold many informal discussions of mutual problems. Judging from the enthusiastic comments we have had, the choice of Professors Wilder and Artin as regular lecturers was a most happy one, and great appreciation was also voiced for the several visiting lecturers who took part in the conference.

The apparent usefulness of this experimental institute has prompted the organization of two similar institutes for next summer. With the advice and assistance of the National Research Council Committee on the Regional Development of Mathematics, the Foundation will sponsor similar institutes at the University of Oregon and the University of North Carolina, following the pattern established at Boulder last year. An experimental venture of another type will also be tried next summer when the Foundation sponsors an institute in mathematics for high school teachers. This institute will be one approach to what appears to be an urgent problem with respect to mathematics in the nation's high schools. I should like to say more on this point a little later.

Another activity in which the Foundation is keenly interested is the regional development of mathematics. This interest is not limited to mathematics, of course. Under the provisions of its Act, the Foundation is directed "to strengthen basic research and education in the sciences, including independent research by individuals throughout the United States, including its Territories and possessions, and to 
avoid undue concentration of such research and education." Using mathematics as an example, I shall describe one way in which the Foundation is attempting to meet this objective. Let us assume a situation in a region of the United States where there exists a university where mathematics has not had effective support. The university has, however, shown its intentions by making good permanent appointments to the mathematics department, by scheduling teaching loads to permit research, and by providing a good library. The Foundation then feels justified in considering assistance by a grant for a research seminar. The grant would be sufficiently large to establish the group for a long enough time to afford stability. The seminar would involve several senior mathematicians with overlapping scientific interests, young Ph.D.'s as associates, and graduate students as assistants. Its purpose would be two-fold: the solution of problems drawn from some broadly conceived field, and the training of young men for research. The first such seminar is being held at the University of Washington, which has been awarded a grant of $\$ 30,000$ for a period of 21 months.

In addition to providing assistance for group efforts, such as conferences, institutes, and seminars, the Foundation is also interested in the individual. Although the Foundation's assistance to individuals normally takes the form of a research grant to an institution for the purpose of aiding research being carried on by one of its staff members, we believe in maintaining flexibility in our operations, to the extent possible, and therefore will consider proposals that may lie outside the regular pattern. For example, in special cases of high merit we may give consideration to proposals that will make possible a leave of absence from teaching for a year in order that an individual may undertake or complete a research project.

A problem that cuts across all the fields of science is the whole matter of scientific information. Such matters as publication, dissemination, cataloging, indexing, abstracting, and so on, are common to the various disciplines of science. Mathematics has an added problem, however, in the complexity and costliness of reproducing mathematical copy. The Foundation has been of some small assistance to the Society in an experimental effort to change from letterpress to photo-offset in the publication of its various journals. I venture to suggest, however, that what is needed is an even broader approach to the problem, with perhaps the experimental use of some of the highly efficient new machines that are beginning to appear on the market. Perhaps the applied mathematicians might join with other scientists and engineers in applying their special skills and ingenuity to some of these vexing problems of communication. 
Another form of NSF assistance in the field of publication is the grant that will make possible the publication of monographs. It has been suggested in several quarters that the more leisurely monograph, expounding a wide field, would provide a welcome departure from the pressures and limitations of writing for journals under present space restrictions. The NSF is glad to have had a part in encouraging this trend through a grant to Professor Alonzo Church, which will aid him to bring out the second volume of his Introduction to mathematical logic.

Turning now from various types of assistance made possible through the grants procedure, I should like to say a few words about our fellowship program, the second of the two major operating programs of the NSF. The National Science Foundation Act authorizes the Foundation "to award ... scholarships and graduate fellowships for scientific study or scientific work in the mathematical, physical, medical, biological, engineering, and other sciences, at accredited nonprofit American or nonprofit foreign institutions of higher education, selected by the recipient of such aid, for stated periods of time." The Act further provides that "Persons shall be selected for such scholarships and fellowships from among citizens of the United States, and such selections shall be made solely on the basis of ability" but in cases of substantially equal ability, where there are not enough awards to go around, selection shall be made in such a way as to result in as wide a geographical distribution as possible.

I have followed rather closely the language of the Act because it covers a number of points on which there has been considerable discussion. One of the points most frequently mentioned, for example, is that NSF fellows have tended to concentrate in a relatively small number of institutions, and these institutions are the ones with the least need for additional support. It will be noted, however, that although the Act makes it possible for the Foundation to take the matter of geography into account in the award of fellowships, the choice of institution is entirely the fellows' and, I believe, quite properly beyond the control of the Foundation. As one of your colleagues has so aptly put it, "This is the American spirit of competition and free enterprise. ..." It is also in the spirit of freedom for research.

Most of you are, I expect, aware that this question has been raised with respect to the concentration of mathematics fellows. We are completely sympathetic with the sincerity and zeal of those who are concerned with the strength and progress of their own institutions. The matter at issue is whether the Foundation, as a Federal agency, should control in any way a fellow's choice of institution. The major- 
ity of those who have expressed themselves to the Foundation on this point feel very strongly that the students' freedom of choice should be protected and maintained. I cannot help believing that solutions to the problems of individual institutions are to be found in measures other than attempts to control the students' choice of institution. In the best interests of progress of research and progress of the individual this must surely be the answer, especially when one considers the high degree of selectivity in the naming of these fellows who were chosen on the basis of nationwide competition.

It is a matter of some interest to note that at least 15 Nobel laureates were students at Cambridge University, 9 of them fellows of Trinity College. The University of Göttingen is also distinguished by the unusual number of Nobel laureates it has produced. Three of them, Heisenberg, 1932; Fermi, 1938; and Pauli, 1945, were associates of Max Born. One wonders how the history of science might have been altered had any of these brilliant minds been diverted from their free choice of institution and teacher.

The statistics with respect to the number of NSF fellows in mathematics are interesting from two standpoints: They indicate that a substantial number of fellowships were awarded in the field of mathematics, in competition with all other fields; and secondly, they show that from an over-all point of view the number of predoctoral fellows in mathematics supported by the Foundation in 1952-53 constituted only 1.8 per cent of the total group of mathematics graduate students throughout the country - a number too small to have very far-reaching effects on the distribution of students among the mathematics departments of the country.

For the academic year 1952-53, 297 applications in the field of mathematics were received, representing 10 per cent of the total number received (2977). The 58 fellows who accepted fellowships in mathematics constituted 10.1 per cent of the total number of fellows (575) supported by NSF in the academic year 1952-53. For the academic year 1953-54, 351 applications in the field of mathematics were received, representing 10.6 per cent of the 3298 applications received. The 55 fellows who were awarded fellowships in mathematics constituted 10.5 per cent of the total number of fellows (522) studying under NSF support during the current academic year. Thus mathematics compares very favorably with other fields in the number of fellowships awarded, being topped only by chemistry and physics last year; and by chemistry, physics, and engineering in the current year.

It would be gratifying if I were able to report that some comparable 
action is taking place with respect to undergraduate study and study in the high schools. Although the Foundation is authorized to award scholarships as well as fellowships, the number and complexity of the problems associated with the award of scholarships in science, especially on a national basis, are such that we have felt it desirable to study this situation thoroughly before taking action. Last fall our Division of Scientific Personnel and Education called an informal meeting of representatives of the educational associations for the purpose of seeking their advice on this knotty problem. The responses of the members of the group were interesting. In only a few instances, for example, was it felt that the stipend associated with the scholarship would prove decisive in influencing a student to attend college. The majority of the group felt that problems of identification and motivation were even greater than the question of furnishing financial aid to undergraduates. The two days of discussion furnished members of the Foundation staff with a number of valuable points to be considered in the formulation of a scholarship program.

The problems of identification and motivation take one back to the secondary school level where, I understand, a critical situation exists with respect to mathematics, and indeed all the sciences. At a recent meeting of our Divisional Committee for the Mathematical, Physical and Engineering Sciences, considerable time was devoted to a discussion of the dearth of high school science teachers. The committee felt that the high school teaching of mathematics and science is of such great importance to the scientific manpower and general welfare of the country that a national program should be developed to improve the situation. Although the problem is too large to be dealt with wholly by any single agency, the Foundation may at least be helpful in pointing the way.

The colleges and universities have long been aware of the difficulties of trying to teach science and mathematics to students who have been inadequately trained in mathematics in high school. As the Nation's scientific manpower needs become more acute, the problem is being recognized in other quarters, also. Mr. Chester H. Lang, vice president of the General Electric Company, addressing a G-E summer institute program for high school teachers of science and mathematics last summer, pointed out that the present scarcity of science high school students threatens to form a bottleneck that will choke off normal American growth. He reported that only 1.4 per cent of the country's high school students study solid geometry; only 1.6 per cent learn trigonometry; and but one-half of one per cent enroll in 
college algebra. Mr. Lang predicted that if this situation continues, "the technological progress we expect will slow to a walk."

The general problems associated with secondary school education, insofar as these are a concern of the Government, are primarily within the purview of the Department of Health, Education and Welfare. The Foundation's participation here is necessarily limited to the fields of mathematics, science and engineering, but we expect to cooperate fruitfully in the broader problems. In particular, I believe that the Foundation's strongest role should be played by studying these problems separately for the different scientific disciplines, e.g., in mathematics by consultation with the mathematicians, in biology with the biologists, and so on. The summer institute for high school teachers of mathematics, which the Foundation is sponsoring at the University of Washington next year, is a small experimental effort. I know that many of you here have given a great deal of thought to some of these problems and we should welcome your comments and your suggestions as to other ways in which the Foundation can strengthen the teaching of mathematics in the secondary schools.

If you are interested in how the rate of effort in mathematics compares with the total Foundation effort, I will mention a few figures. In fiscal year 1954, the NSF budget for the support of research totals approximately $\$ 4$ million - half of which was allocated to the mathematical, physical, and engineering sciences. Of this, the allocation to mathematics is approximately $\$ 161,000$, which includes about $\$ 12,000$ for conferences and travel to foreign meetings.

If one adds the funds expended, or to be expended, for the advancement of mathematics through the Division of Scientific Personnel and Education, one finds $\$ 142,000$ for fellowship awards, and $\$ 54,000$ for conferences and for the mathematics section of the National Register. These figures, added to the previous ones, give a grand total of $\$ 357,000$. Thus a little over five per cent of the total NSF funds are being used for the support of mathematics in various ways. Undoubtedly this is not as much as any of us could desire, and yet when we consider among how many fields the NSF dollar must be split, probably mathematics is not faring too badly.

It is especially gratifying to us in the Foundation that we should be supporting a lively program in mathematics; for mathematics, in a sense, bridges the gap, real or imaginary, which exists between the sciences and the humanities. The exigencies of modern technology have attracted many of the sciences away from their original orbits in the realm of natural philosophy. Mathematics, too, has had its 
practical part to play in the modern world, but in the process it has never lost its scholarly aura. It occupies an honored place perhaps equally among the humanities as among the physical sciences. It is rather pleasant to think of mathematics as Whitehead ${ }^{1}$ thought of it when he said:

"I will not go so far as to say that to construct a history of thought without profound study of the mathematical ideas of successive epochs is like omitting Hamlet from the play which is named after him. That would be claiming too much. But it is certainly analogous to cutting out the part of Ophelia. This simile is singularly exact. For Ophelia is quite essential to the play, she is very charming-and a little mad. Let us grant that the pursuit of mathematics is a divine madness of the human spirit, a refuge from the goading urgency of contingent happenings."

National Science Foundation

${ }^{1}$ A. N. Whitehead, Science and the modern world, 1st ed., New York, Macmillan, 1925. 